\title{
Monoclonal antibody to tumor necrosis factor-related apoptosis-inducing ligand receptor 2 (TRAIL-R2) induces apoptosis in primary renal cell carcinoma cells in vitro and inhibits tumor growth in vivo
}

\author{
Y.ZENG ${ }^{1}$, X.X. WU ${ }^{1}$, M. FISCELLA ${ }^{2}$, O. SHIMADA ${ }^{1}$, R. HUMPHREYS ${ }^{2}$, V. ALBERT ${ }^{2}$ and Y. KAKEHI ${ }^{1}$ \\ ${ }^{1}$ Department of Urology, Faculty of Medicine, Kagawa University, 1750-1 Oaza Ikenobe, Miki-cho, Kita-gun, \\ Kagawa 761-0793, Japan; ${ }^{2}$ Antibody Development Department, Human Genome Sciences, Inc., Rockville, MD 20850, USA
}

Received October 3, 2005; Accepted November 25, 2005

\begin{abstract}
Tumor necrosis factor-related apoptosis-inducing ligand (TRAIL) triggers apoptosis in a variety of tumor cells through two of its receptors: TRAIL-R1 and TRAIL-R2. We investigate the susceptibility of human renal cell carcinoma (RCC) cells to TRM-1 and HGS-ETR2, 2 human monoclonal agonistic antibodies specific for TRAIL-R1 and TRAIL-R2, respectively. HGS-ETR2 effectively induced apoptotic cell death in 10 of 11 cell cultures, including 2 human RCC cell lines and 9 human primary RCC cell cultures, with a more pronounced effect after preincubation with anti-human IgG Fc. In contrast, TRM-1 was effective in only 1 primary RCC cell culture. The increased effectiveness of HGS-ETR2 for inducing cell death might have been affected by differences in the cell-surface expression of the 2 TRAIL receptors, namely that TRAIL-R2 but not TRAIL-R1 was frequently expressed in most of the RCC cells tested. The activities of caspase-9, $-8,-6$, and -3 were increased with HGS-ETR2-induced apoptosis, and cell death could be blocked by specific caspase inhibitors for caspase- $9,-8$, and -3 , and the general caspase inhibitor. In vivo administration of HGS-ETR2 with or without cross-linker significantly suppressed tumor growth of subcutaneously inoculated human RCC xenografts in immunodeficient mice. These results suggest the potential utility of TRAIL-R2 antibody as a novel therapeutic agent in RCC.
\end{abstract}

\section{Introduction}

Renal cell carcinoma (RCC) remains one of the most drugresistant malignancies because of the lack of an effective therapy (1-3). It had been found that only about $9 \%$ of 39

Correspondence to: Dr X.X. Wu, Department of Urology, Faculty of Medicine, Kagawa University, 1750-1 Oaza Ikenobe, Miki-cho, Kita-gun, Kagawa 761-0793, Japan

E-mail:wuxian@med.kagawa-u.ac.jp

Key words: renal cell carcinoma, TRAIL-R2, mAb, apoptosis potential therapeutic agents have some benefits (4). Although IFN- $\alpha$ and interleukin-2 have been widely used for treating $\mathrm{RCC}$, the overall response rate reached a maximum of only $20 \%$ (5). More effective therapies, including targeted therapies, are clearly needed.

Tumor necrosis factor-related apoptosis (TNF)-inducing ligand (TRAIL), a proapoptotic member of the TNF superfamily (6), has potential as an effective anticancer agent because it selectively induces apoptosis in a variety of cancer cells, yet is relatively non-toxic to normal cells (7-13). In a previous study, we showed that TRAIL combined with adriamycin induced significant apoptosis in human RCC cells. However, TRAIL monotherapy was not as effective (14). TRAIL triggers apoptosis by binding to 2 receptors: TRAILR1 (DR4) and TRAIL-R2 (DR5) $(15,16)$. The activation of these receptors results in a signal transduction cascade that initiates both intrinsic (mitochondrial) and extrinsic apoptotic pathways $(17,18)$. In addition, TRAIL binds to 2 other receptors, TRAIL-R3 (DcR1) and TRAIL-R4 (DcR2), which lack a functional cytoplasmic death domain, and to a secreted TNF receptor homologue: osteoprotegerin $(15,16,19)$. These receptors have been proposed to inhibit TRAIL-induced apoptosis by acting as DcRs. Potentially, the degree of TRAILR1 and TRAIL-R2-mediated apoptosis induced by TRAIL might be lowered in the presence of TRAIL-R3 and TRAILR4 activation. Transfection of DcRs into TRAIL-sensitive cells renders them TRAIL-resistant $(15,20,21)$. However, expression of DcRs can be found on tumor cells that are capable of responding to TRAIL. Use of a specific activator of TRAIL-R1 or TRAIL-R2 is preferable to exclude interference from competition with DcRs. Most normal tissues and cells do not show detectable cell-surface expression of TRAIL-R2, and are resistant to TRAIL-R2-mediated apoptosis (22-24), although TRAIL-R2 mRNA is detectable in some normal tissues (17). In contrast, a large number of tumor tissues and tumor cell lines express high levels of TRAIL-R2, and are susceptible to TRAIL-R2-mediated apoptosis $(25,26)$. Therefore, selective targeting of TRAIL-R2 might provide a novel and promising therapeutic strategy for human cancers. In the present study, we show that a human TRAIL-R2 mAb, HGSETR2, effectively induces apoptosis in RCC cell lines and primary RCC cell cultures, and suppresses tumor growth of 
subcutaneously inoculated human RCC xenografts in immunodeficient mice. These findings suggest that HGS-ETR2 should be evaluated as a potential RCC therapy.

\section{Materials and methods}

Regents. The human TRAIL-R1 monoclonal antibody (mAb; TRM-1) and TRAIL-R2 mAb (HGS-ETR2) were kindly provided by Human Genome Sciences, Inc. (Rockville, MD). TRM-1 and HGS-ETR2 are fully human monoclonal antibodies $\left(\mathrm{IgG}_{1}\right)$ isolated using phage-display technology in collaboration with Cambridge Antibody Technology (CAT) (27). ELISA and/or BIAcore analyses determined that TRM-1 and HGS-ETR2 are highly specific for binding to TRAIL-R1 and TRAIL-R2, respectively. Recombinant human TRAIL, a 19.6 $\mathrm{kDa}$ protein consisting of 169 amino acid residues, was purchased from PeproTech EC (London, UK). PE-conjugated anti-human TRAIL-R1 (mouse $\mathrm{IgG}_{1}$ ) and TRAIL-R2 (mouse $\mathrm{IgG}_{2 \mathrm{~b}}$ ) for flow cytometry were purchased from Genzyme Techne (Minneapolis, MN). Mouse $\mathrm{IgG}_{1}$ and mouse $\mathrm{IgG}_{2 \mathrm{~b}}$ isotype control (PE-conjugated) were purchased from Southern Biotech (Birmingham, AL). Annexin-V FITC apoptosis detection kit was purchased from MBL (Nagoya, Japan). Mouse anti-human $\operatorname{IgG~Fc}$, and the caspase inhibitors, ZLEHD-FMK, Z-LETD-FMK, Z-DQMD-FMK, were purchased from Sigma (St. Louis, MO). The general caspase inhibitor Z-VAD-FMK was purchased from ICN Pharmaceuticals (Aurora, $\mathrm{OH}$ ).

RCC cell lines and primary RCC cells. Two human RCC cell lines, Caki-1 and ACHN, were purchased from American Type Culture Collection (Rockville, MD). Primary RCC cells (RCC1, RCC2, RCC3, RCC4, RCC5, RCC6, RCC7, RCC8, and RCC9) were separated from surgical specimens of 9 patients with untreated RCC, as described previously (28). All patients had been diagnosed as RCC of the alveolar type and clear cell subtype by histological examination. Pathological grading and staging were consistent with the WHO criteria (World Health Organization 2000) as follows: a) patient no. 1 (RCC1), $\mathrm{T}_{2} \mathrm{~N}_{4} \mathrm{M}_{0}$, grade 2 ; b) patient no. 2 (RCC2), $\mathrm{T}_{2} \mathrm{~N}_{0} \mathrm{M}_{0}$, grade 2 ; c) patient no. 3 (RCC3), $\mathrm{T}_{2} \mathrm{~N}_{0} \mathrm{M}_{0}$, grade 2 ; d) patient no. 4 (RCC4), $\mathrm{T}_{2} \mathrm{~N}_{0} \mathrm{M}_{0}$, grade 1 ; e) patient no. 5 (RCC5), $\mathrm{T}_{2} \mathrm{~N}_{0} \mathrm{M}_{0}$, grade 2; f) patient no. 6 (RCC6), $\mathrm{T}_{2} \mathrm{~N}_{0} \mathrm{M}_{0}$, grade $2 ; \mathrm{g})$ patient no. 7 (RCC7), $\mathrm{T}_{3 \mathrm{~b}} \mathrm{~N}_{1} \mathrm{M}_{0}$, grade $2 ; \mathrm{h}$ ) patient no. 8 (RCC8), $\mathrm{T}_{2} \mathrm{~N}_{0} \mathrm{M}_{0}$, grade 1; and i) patient no. 9 (RCC9), $\mathrm{T}_{3 \mathrm{~b}} \mathrm{~N}_{0} \mathrm{M}_{1}$, grade 2 . Cells have $<5 \%$ contamination with nonmalignant cells, as judged by morphological examination of Wright-Giemasa-stained smears, and were used as RCC cells. All primary RCC cells used in this study showed little or limited susceptibility to IFN- $\alpha$, IFN- $\gamma$, vinblastine, 5fluorouracil, or adriamycin (unpublished data).

Cell viability inhibition assay. Cell viability inhibition was assessed by 3-(4,5-dimethylthiazol-2-yl)-2,5-diphenyltetrazolium bromide (MTT) assay as described previously (28). Briefly, a 100- $\mu 1$ suspension of 5000 cells was seeded into a 96-well flat-bottom microtiter plate. After incubation for $24 \mathrm{~h}$, $100 \mu 1$ of mAb (TRM-1 or HGS-ETR2), TRAIL/Apo2L, or medium (control) was added to the plates, and each plate was incubated for an additional 24-72 h, followed by addition of $20 \mu \mathrm{l}$ of MTT working solution ( $5 \mathrm{mg} / \mathrm{ml}$, Sigma) for $4 \mathrm{~h}$, and then $150 \mu 1$ of isopropanol supplemented with $0.05 \mathrm{~N}$ hydrochloric acid for $30 \mathrm{~min}$. Absorbance (A) was measured using a microplate reader (Bio-Rad, Tokyo, Japan) at $570 \mathrm{~nm}$ with a $630 \mathrm{~nm}$ reference, and viability was represented as a percentage of control cells [percent cell viability $=$ (treated/ control) x 100]. In some experiments, TRM-1 or HGS-ETR2 was preincubated with mouse anti-human IgG Fc (TRM-1-Fc, HGS-ETR2-Fc) at a ratio of $1: 1$ for at least $30 \mathrm{~min}$ at $4^{\circ} \mathrm{C}$.

Flow cytometric analysis of TRAIL-R1 and TRAIL-R2. RCC cells were removed from the substrate using $0.05 \%$ trypsin and $0.02 \%$ EDTA, and were further incubated in medium for $10 \mathrm{~h}$ on a rocker platform to enable regeneration of the receptors. Cells were then harvested and washed 3 times in isotonic PBS containing $0.5 \%$ BSA (PBSA), and were resuspended in the same buffer to a final concentration of $4 \times 10^{6}$ cells $/ \mathrm{ml}$. Cells $(25 \mu \mathrm{l})\left(1 \times 10^{5}\right)$ were transferred to a $5-\mathrm{ml}$ tube, and $10 \mu \mathrm{l}$ of PE-conjugated anti-TRAIL-R1 or antiTRAIL-R2 reagent was added. After incubation for $45 \mathrm{~min}$ at $4^{\circ} \mathrm{C}$, the cells were resuspended in $300 \mu 1$ of PBSA buffer for a final flow cytometric analysis with EPICS XL (Beckman Coulter, Miami, FL). The control consisted of cells in a separate tube treated with PE-labeled mouse $\mathrm{IgG}_{1}$ or mouse $\mathrm{IgG}_{2 \mathrm{~b}}$. The relative fluorescence intensity (RFI) was determined by calculating the ratio of mean fluorescence intensity for specific staining to control staining.

Apoptosis detections. Apoptosis was determined in two ways. According to the first method, RCC cells were treated by HGS-ETR2-Fc for 6-12 h, and then washed twice with cold PBS, resuspended in a binding buffer at a concentration of $5 \times 10^{5}$ cells/ml. Subsequently, $5 \mu 1$ Annexin V-FITC and $5 \mu 1$ propidium iodide (PI) were added, and cells were analyzed by flow cytometry. According to the second method, both floating and adherent cells were harvested following incubation with HGS-ETR2-Fc for $24 \mathrm{~h}$. Cells were stained with $1 \mu \mathrm{g} / \mathrm{ml}$ Hoechst 33342 (Sigma) at $37^{\circ} \mathrm{C}$ for $30 \mathrm{~min}$, and observed under a fluorescent microscope BX51 (Olympus, Tokyo, Japan).

Caspase activity and caspase inhibition assays. Caspase-9, $-8,-6$, and -3 activities were measured using a colorimetric assay with caspase-9, $-8,-6$, and -3 Colorimetric Protease Assay kits (MBL) as described previously (29). The caspase inhibition assay was performed with the caspase-9 inhibitor Z-LEHD-FMK, caspase-8 inhibitor Z-LETD-FMK, caspase-3 inhibitor Z-DQMD-FMK, and a general caspase inhibitor ZVAD-FMK. Cells were pretreated with these reagents at a concentration of $50 \mu \mathrm{M}$ for $1 \mathrm{~h}$, and then were incubated with HGS-ETR2-Fc for $72 \mathrm{~h}$. As a positive control, cells were pretreated with the caspase inhibitor, followed by incubation with medium; as a negative control, cells were pretreated with medium followed by treatment with mAbs. Cell viability inhibition was assessed by MTT assay.

Western blot analysis. Cells $\left(1 \times 10^{6}\right)$ were plated in $100-\mathrm{mm}$ dishes for $24 \mathrm{~h}$ and then treated with the indicated concentrations of $\mathrm{HGS}-\mathrm{ETR} 2-\mathrm{Fc}$ for $3-24 \mathrm{~h}$ at $37^{\circ} \mathrm{C}$ in a cell 
a)

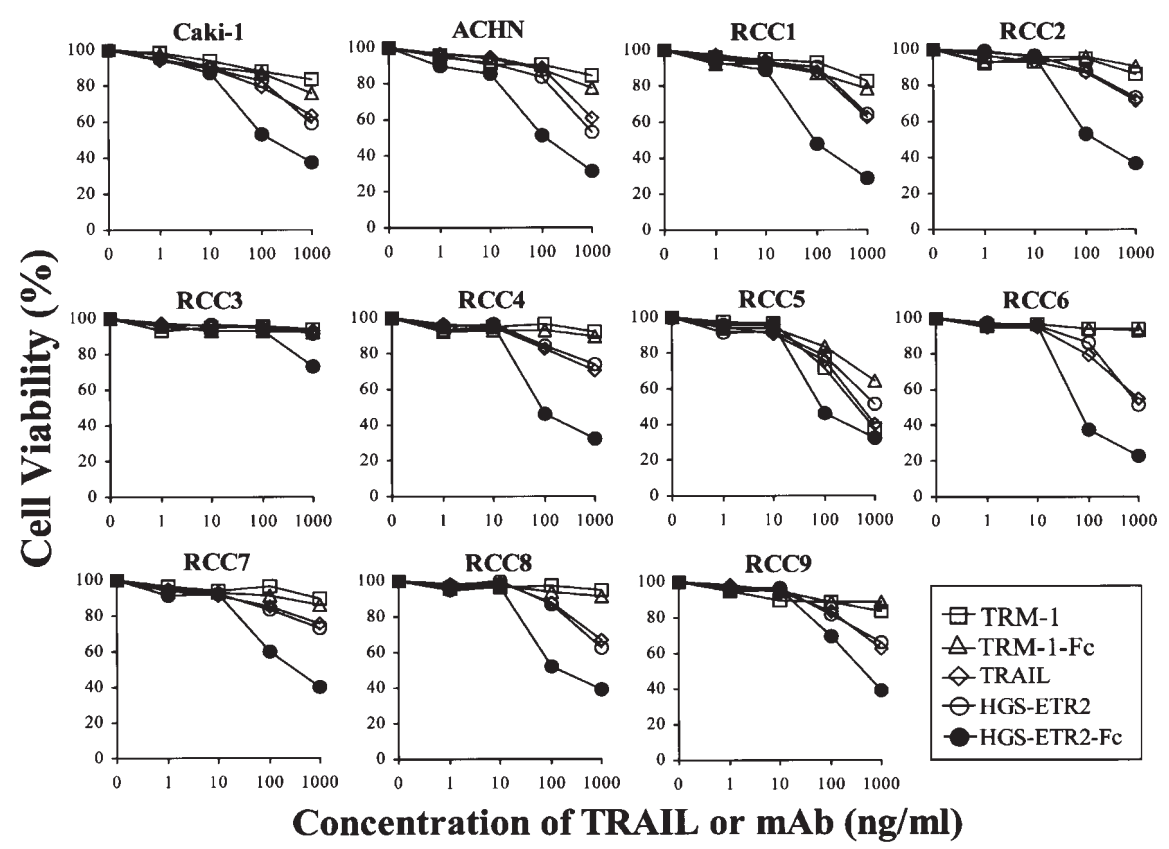

b)

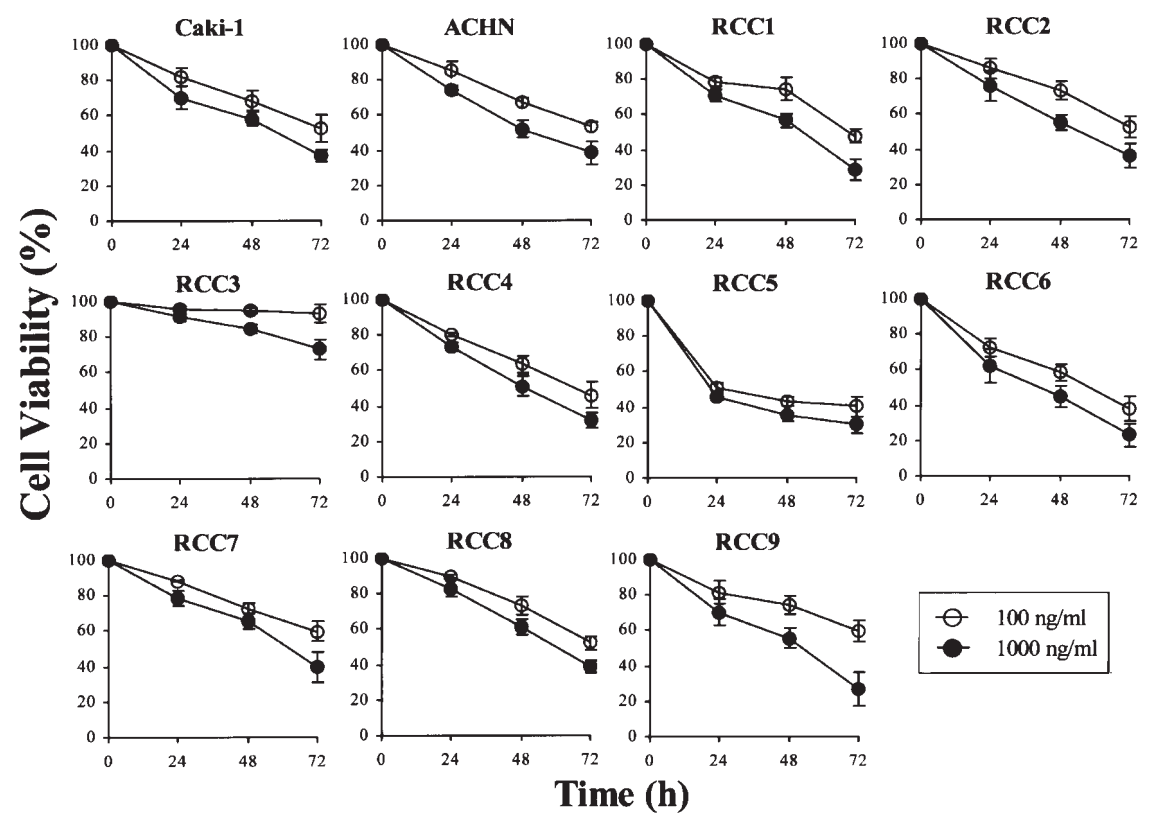

Figure 1. Dose- and time-dependent cytotoxic effects of TRM-1, HGS-ETR2, and TRAIL in RCC cells. (a) Two RCC cell lines, Caki-1 and ACHN, and 9 primary RCC cell cultures were treated with serially diluted concentrations of TRM-1, HGS-ETR2, TRM-1-Fc, HGS-ETR2-Fc, and TRAIL for $72 \mathrm{~h}$. (b) RCC cells were treated with HGS-ETR2-Fc for 24-72 h. Cell viability was determined by MTT assay. The results are derived from three experiments.

culture incubator. Cells were lysed for $20 \mathrm{~min}$ at $4^{\circ} \mathrm{C}$ in a lysis buffer [1\% Triton X-100, $20 \mathrm{mM}$ Tris- $\mathrm{HCl}(\mathrm{pH} 8.0)$, $150 \mathrm{mM} \mathrm{NaCl}, 1 \mu \mathrm{g} / \mathrm{ml}$ leupeptin, $2 \mathrm{mM}$ PMSF, and $1 \mathrm{mM}$ DTT]. Protein concentration of the extracts was determined by Bio-Rad colorometric assay (Bio-Rad, Hercules, CA). Protein $(50 \mu \mathrm{g})$ was separated on an SDS-PAGE and transferred to nitrocellulose membrane (Bio-Rad). The membranes were incubated with specific Abs of poly(ADPribose) polymerase (PARP) (Trevigen, Gaithersburg, MD), caspase-6 (MBL), and caspase-3 (Santa Cruz Biotechnology,
Santa Cruz, CA). The bands corresponding to specific proteins were detected by HRP-conjugated secondary Abs and enhanced chemiluminescence (Amersham, Piscataway, NJ).

In vivo treatments. In experiment 1,3 primary $\mathrm{RCC}$ cells (RCC2, RCC4, and RCC6) (5x106 cells) were suspended in $0.2 \mathrm{ml} \mathrm{PBS}$, and injected subcutaneously into both flanks of male CB.17 SCID/SCID mice (Clea, Japan Inc., Tokyo, Japan), 4-5 weeks of age. Treatment was initiated when the tumor reached 6-7 $\mathrm{mm}$ in diameter (a mean tumor volume 
a)

TRAIL-R1
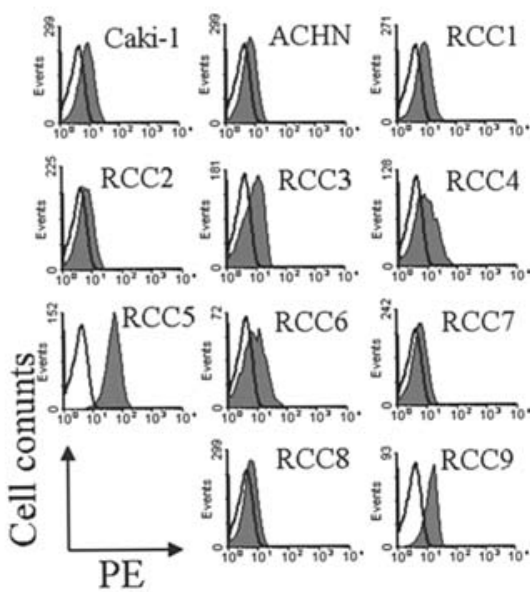

TRAIL-R2
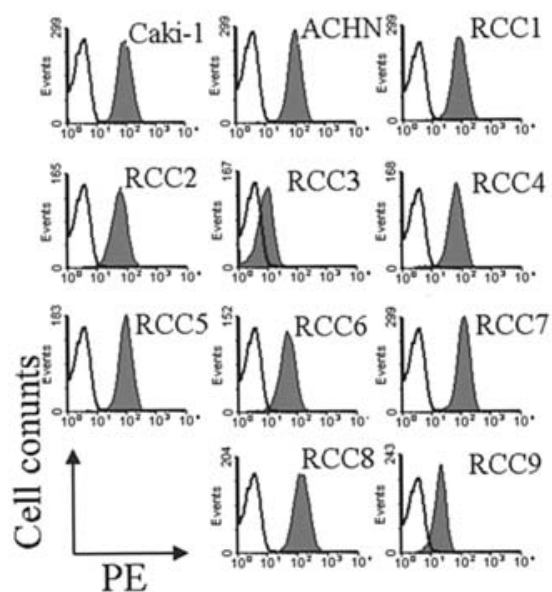

$\mathrm{PE}$

b)
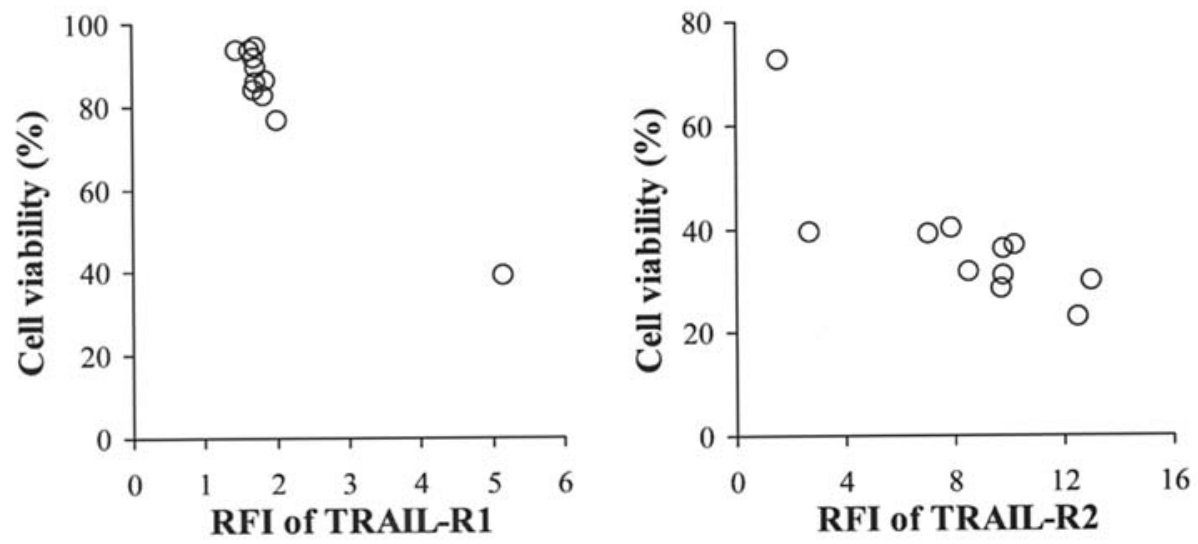

Figure 2. Cell-surface expression of TRAIL-R1 and TRAIL-R2 and their relationships with cell viability of TRM-1 or HGS-ETR2-Fc. (a) Expression of TRAIL-R1 and TRAIL-R2. Two RCC cell lines, Caki-1 and ACHN, and 9 primary RCC cell cultures were incubated with mouse IgG, or mouse anti-human TRAIL-R1/-R2 mAb, and analyzed by flow cytometry. Shaded and unshaded peaks correspond to specific and control staining, respectively. (b) The relationships between the level of TRAIL-1 or TRAIL-R2 expression and TRM-1 or HGS-ETR2-Fc sensitivity were analyzed in all RCC cells. The vertical axes represent the percent cytotoxicity induced by TRM-1 $(1000 \mathrm{ng} / \mathrm{ml})$ or HGS-ETR2-Fc $(1000 \mathrm{ng} / \mathrm{ml})$ for $72 \mathrm{~h}$. RFI, relative fluorescence intensity.

of $\left.150 \mathrm{~mm}^{3}\right)$. HGS-ETR2 $(100 \mu \mathrm{g} / 200 \mu \mathrm{l})$ preincubated with mouse anti-human IgG Fc at a ratio of 1:1 was administered daily by intraperitoneal (i.p.) injection for 14 days. Mice in control groups received PBS $(200 \mu 1)$ by i.p. injection. In experiment 2, RCC6 was implanted into the right flank of BALB/c nude mice (Clea, Japan Inc.), 4-5 weeks of age, using the same method as in experiment 1. HGS-ETR2 (100 or $300 \mu \mathrm{g} / 200 \mu \mathrm{l}$ ) was administered daily by i.p. injection for 14 days. In both experiments, the mice were weighed on a weekly basis. Tumors were measured every 3 days, and the relative tumor volumes were calculated as described (30). At the time points indicated, the mice were sacrificed under ether anesthesia, and tumors, livers, kidneys, and lungs were dissected, fixed in neutral-buffered formalin, and embedded in paraffin for further study. All treatment protocols were approved by the animal care and use committee of the Kagawa University, Japan.

Statistical analysis. All determinations were made in triplicate, and the results were expressed as mean \pm SD. Significance was analyzed by Student's t-test or analysis of variance (ANOVA).

\section{Results}

Effects of TRM-1, HGS-ETR2, and TRAIL on human RCC cells. Two human RCC cell lines and 9 primary RCC cell cultures were examined for their susceptibility to the cytotoxic effects of TRM-1, HGS-ETR2, or TRAIL. As shown in Fig. 1a, only RCC5 exhibited a dose-dependent cell viability inhibition response to TRM-1 treatment. Other cell cultures exhibited limited sensitivity to TRM-1, with loss of cell viability reaching a maximum of $20 \%$ at the highest dose $(1000 \mathrm{ng} / \mathrm{ml})$. In contrast, treatment with $1000 \mathrm{ng} / \mathrm{ml}$ of HGS-ETR2 induced $25-50 \%$ of loss of cell viability in all cell cultures except RCC3. Preincubation of HGS-ETR2 with mouse anti-human IgG Fc enhanced cell death induced by HGS-ETR2 in most RCC cells. However, we did not observe a similar enhancement with anti-human IgG Fc combined with TRM-1. In addition, the cytotoxic effect of TRAIL was investigated. In the HGS-ETR2 sensitive cells, TRAIL was as effective as HGS-ETR2 for inducing cell death, but it was weaker than HGS-ETR2-Fc. RCC3, which was insensitive to HGS-ETR2, and was also resistant to TRAIL (Fig. 1a). 
a)

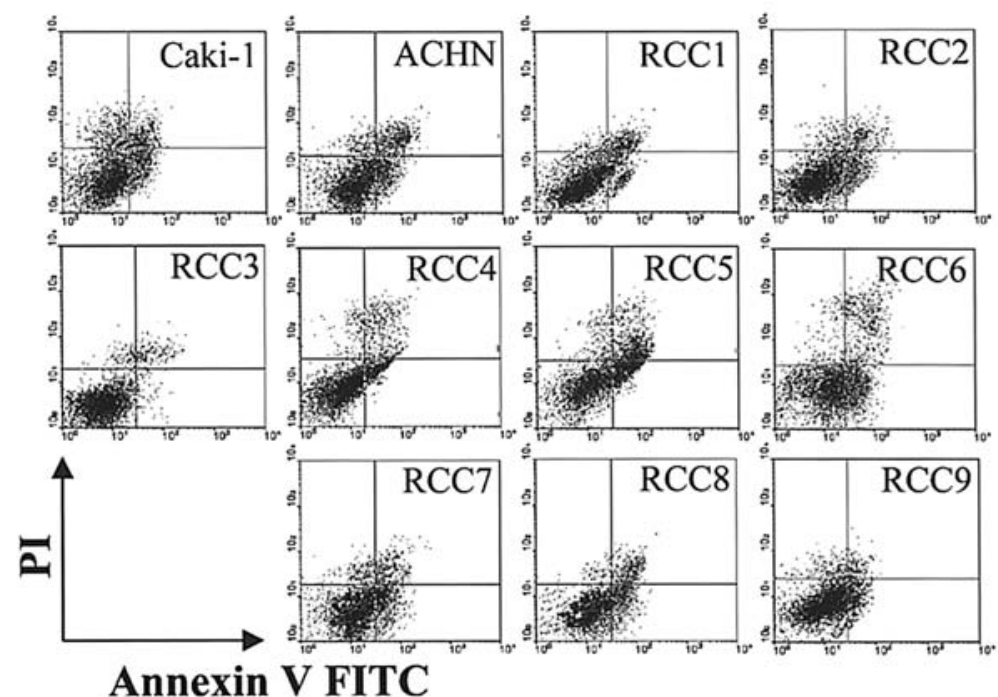

Annexin V FITC

b)
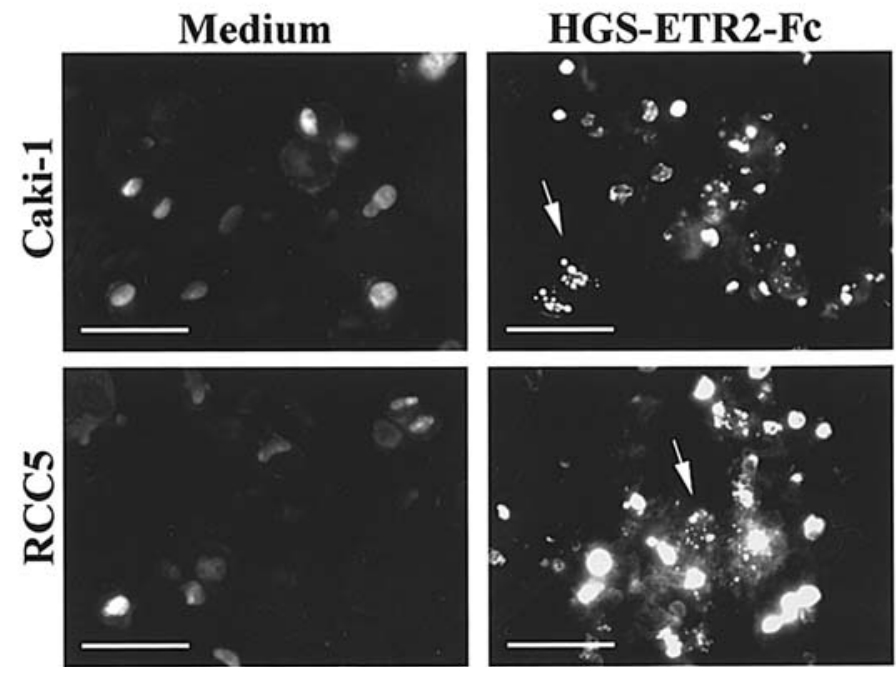

Figure 3. Apoptosis induced by HGS-ETR2-Fc. (a) Flow cytometric analysis of apoptotic cells. RCC cells were treated with medium or HGS-ETR2-Fc (1000 ng/ $\mathrm{ml}$ ) for $6 \mathrm{~h}$, and then were stained with Annexin V-FITC and PI. Annexin V-FITC- and PI-positive cells were measured by flow cytometry. (b) Representative fluorescence microscopy observation of apoptotic cells. RCC cells were treated with medium or HGS-ETR2-Fc (1000 ng/ml) for $24 \mathrm{~h}$, and then were stained with Hoechst 33342. A number of apoptotic cells with nucleus condensation and fragmentation were observed (arrows). Bars are $100 \mu \mathrm{m}$ in all panels.

The loss of cell viability induced by HGS-ETR2-Fc was examined over time in RCC cells (Fig. 1b). A 24-h treatment with HGS-ETR2-Fc induced up to $40 \%$ cell death in all HGSETR2-sensitive cells, with the exception of RCC5, which showed increased sensitivity to this treatment ( $50 \%$ cell death).

Expression of TRAIL-R1 and TRAIL-R2 on the surface of human RCC cells. To investigate whether the sensitivity of RCC cells to TRM-1 or HGS-ETR 2 depends on their receptors, the cell-surface expression of TRAIL-R1 and TRAIL-R2 was examined by flow cytometry. Only 1 of 11 RCC cell cultures (RCC5) expressed TRAIL-R1, whereas TRAIL-R2 was strongly expressed in 10 of 11 cell cultures including 2 cell lines, ACHN and Caki-1 (Fig. 2a). Interestingly, the TRAIL-
R1 positive cells, RCC5, were the only cells sensitive to TRM-1. By analogy, HGS-ETR2-resistant cells RCC3 only weakly expressed TRAIL-R2 (Fig. 2b). These results suggest a correlation between the cell-surface expression of TRAIL-R2 and the inhibition of cell viability induced by HGS-ETR2 and HGS-ETR2-Fc.

HGS-ETR2 triggers apoptosis in sensitive RCC cells. The ability of HGS-ETR2-Fc to induce cell death in sensitive RCC cells by apoptosis was evaluated by both flow cytometry and Hoechst 33342 staining. Flow cytometric analysis following Annexin V and PI staining showed the apoptosis induced by HGS-ETR2-Fc (Fig. 3a). Early and late apoptotic cells were found in all of the sensitive cell cultures after treatment with 
a)

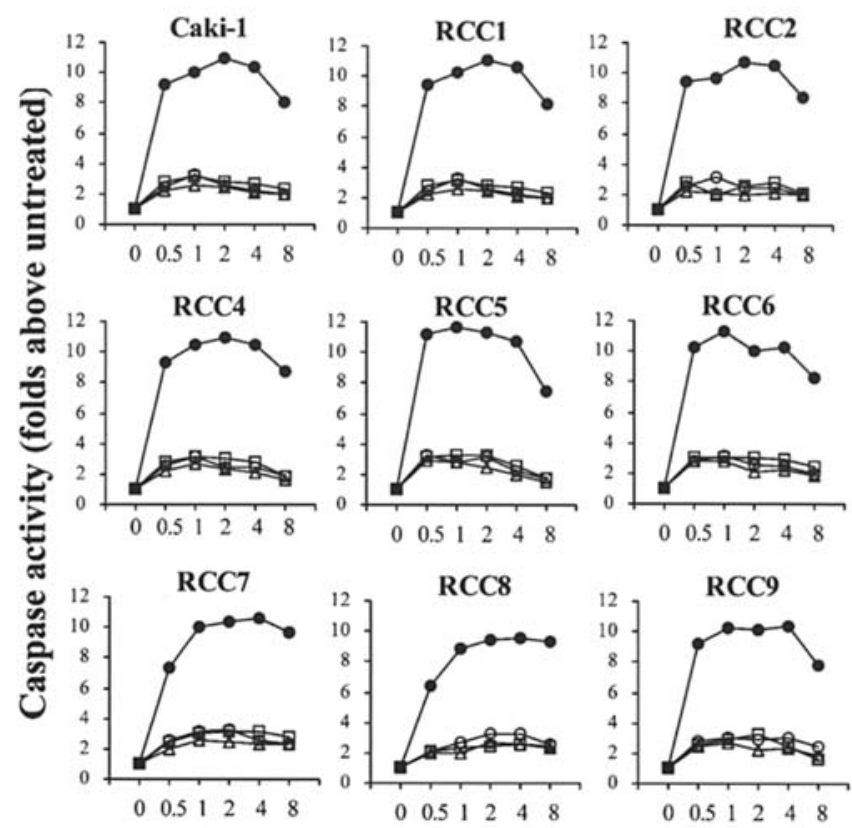

Time (h)

b)

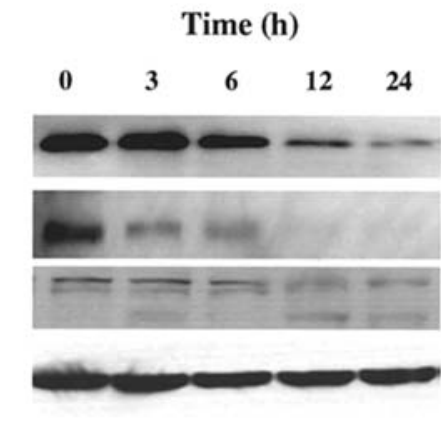

RCC6
Concentration $(\mathrm{ng} / \mathrm{ml})$

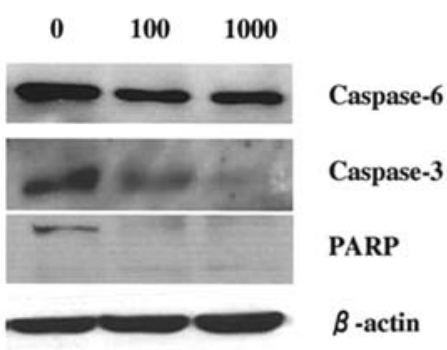

RCC8

Figure 4. Activation of caspases by HGS-ETR2-Fc. (a) Caki-1 and eight sensitive primary RCC cells were treated with HGS-ETR2-Fc (1000 ng/ml) for 0-8 h.

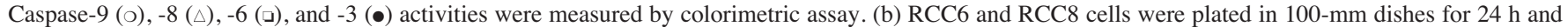
then treated with the indicated concentrations of HGS-ETR2-Fc for 3-24 h. Caspase-6, -3, and PARP activities were determined by Western blot analysis as described in Materials and methods. B-actin was used as loading control.

Table I. The effects of caspase inhibitors on HGS-ETR2-Fc-induced cell death of Caki-1 and eight sensitive primary RCC cell cultures.

Cell viability $(\%)$

\begin{tabular}{|c|c|c|c|c|c|c|c|c|c|}
\hline Treatment & Caki-1 & $\mathrm{RCC1}$ & $\mathrm{RCC} 2$ & RCC4 & RCC5 & RCC6 & RCC7 & RCC8 & RCC9 \\
\hline HGS-ETR2-Fc + medium & 37.1 & 28.4 & 36.2 & 31.8 & 29.1 & 22.9 & 40.1 & 39.1 & 26.8 \\
\hline HGS-ETR2-Fc + Z-VAD-FMK & 93.5 & 94.2 & 92.6 & 94.9 & 96.5 & 92.8 & 91.7 & 97.3 & 94.7 \\
\hline HGS-ETR2-Fc + Z-DQMD-FMK & 73.2 & 71.1 & 67.7 & 66.8 & 69.6 & 66.6 & 64.2 & 67.3 & 68.6 \\
\hline HGS-ETR2-Fc + Z-LETD-FMK & 85.9 & 87.3 & 79.2 & 87.9 & 81.2 & 79.6 & 76.3 & 78.6 & 80.5 \\
\hline HGS-ETR2-Fc + Z-LEHD-FMK & 82.3 & 84.9 & 81.1 & 81.4 & 78.1 & 78.8 & 72.6 & 82.1 & 76.7 \\
\hline
\end{tabular}

Tumor cells were preincubated with $50 \mu \mathrm{M}$ caspase inhibitors or medium for $1 \mathrm{~h}$, and were then treated with $1000 \mathrm{ng} / \mathrm{ml} \mathrm{HGS}-\mathrm{ETR} 2-\mathrm{Fc}$ for another $72 \mathrm{~h}$. Cell viability was determined by MTT assay. Values represent the mean of three independent experiments with an SD $\leq 10 \%$, and $\mathrm{P}<0.01$ when comparing each caspase inhibitor treatment to medium in all RCC cells. 
$1000 \mathrm{ng} / \mathrm{ml}$ HGS-ETR2-Fc, whereas few cells of resistant RCC3 showed as apoptotic at the same time point. Nuclear condensation and fragmentation, which are characteristics of apoptosis, were observed in Caki-1 and RCC5 cells after treatment with $1000 \mathrm{ng} / \mathrm{ml}$ HGS-ETR2-Fc for $24 \mathrm{~h}$ (Fig. 3b). These data show that the in vitro cytotoxicity of HGS-ETR2Fc is mediated by apoptosis.

Caspase cascade in sensitive RCC cells treated with HGSETR2. Caspase activation is the final common molecular event required for executing apoptosis in most biological systems (31). To investigate caspase activation, cell lysates obtained after treating 9 sensitive RCC cells with HGSETR2-Fc were incubated with each of the chromogenic substrates for caspase- $9,-8,-6$, and -3 . There was an increase in activity with time for all of the above caspases in an almost synchronous manner (Fig. 4a). Caspase activity increased 30 min after starting treatment, and reached a peak level after 1-4 h of incubation. Activity decreased gradually over time, but remained above baseline levels after $8 \mathrm{~h}$. Dose- and timedependent activation of PARP, caspase- 6 , and -3 was also observed after treating RCC cells with HGS-ETR2-Fc by Western blot analysis (Fig. 4b).

To further examine the involvement of caspases in TRAIL receptor-triggered apoptosis, the effects of the caspase inhibitors Z-LEHD-FMK, Z-LETD-FMK, Z-DQMD-FMK, and Z-VAD-FMK specific to caspase-9, -8, -3, and all caspases, respectively, were tested in HGS-ETR2-Fc-treated Caki-1 and 8 primary RCC cell cultures. As shown in Table I, all of the caspase inhibitors effectively blocked HGS-ETR2Fc-induced cell death, indicating that cell death is caspasedependent, although the effect of Z-VAD-FMK was the most pronounced and Z-DQMD-FMK was relatively low. Z-LEHDFMK and Z-LETD-FMK effectively blocked HGS-ETR2-Fcinduced cell death to a similar extent, suggesting the important roles of caspase- 9 and caspase- 8 in this apoptotic pathway.

Inhibition of RCC xenograft growth in immunodeficient mice. To confirm the anticancer activity of HGS-ETR2, 2 in vivo experiments were carried out. In experiment 1, a SCID mouse xenograft model engrafted with primary RCC cells was used to evaluate 3 primary RCC cell samples for HGS-ETR2-Fc sensitivity (RCC2, RCC4, and RCC6). Comparison of the growth rates of these tumors revealed obvious variability among tumors. RCC6 (Fig. 5a) displayed almost a 2-fold greater final tumor volume compared to RCC4 (Fig. 5b). This heterogeneity of growth rate is typical of primary human cells when transplanted into SCID mice, and may reflect inherent patient-to-patient differences. Treatment with a $100-\mu \mathrm{g}$ dose of HGS-ETR2-Fc for 14 days significantly inhibited the growth of all 3 tumors $(\mathrm{P}<0.01$ in RCC2 and RCC6, and $\mathrm{P}<0.05$ in RCC4) (Fig. 5).

In experiment 2 , the rapidly growing RCC6 was selected for further investigation of the anti-tumor activity of HGSETR2. Nude mice were treated with either 100- or 300- $\mu \mathrm{g}$ doses of HGS-ETR2 for 14 days, and tumor growth was observed during the treatment period and for 4 weeks after cessation of treatment (Fig. 6a). Dose-dependent growth inhibition was seen with HGS-ETR2 treatment, and this inhibition was significant at both doses $(\mathrm{P}<0.01)$ (Fig. 6a a)

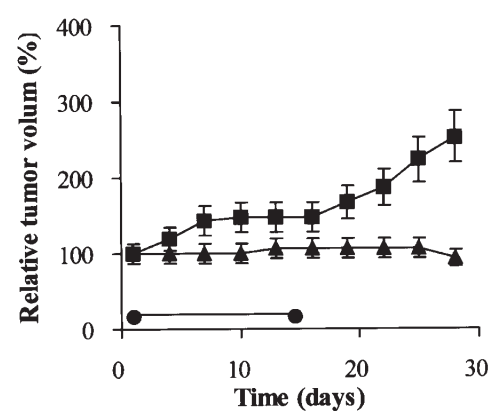

b)

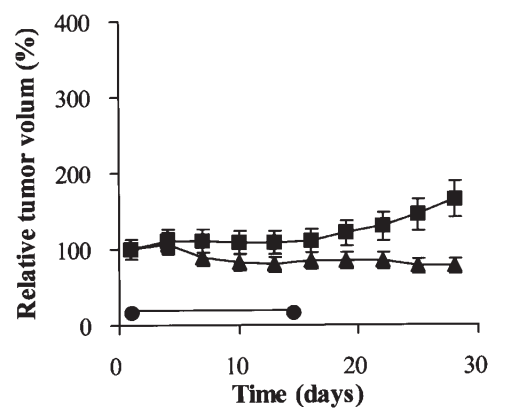

c)

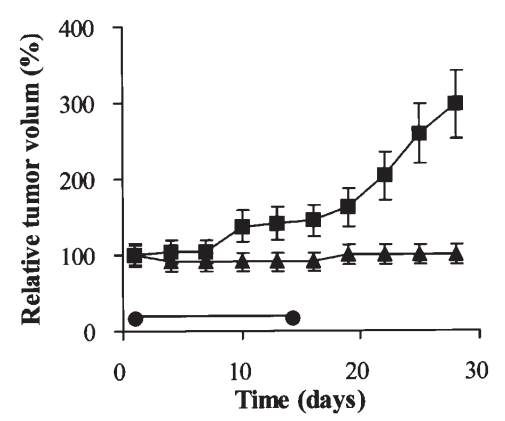

Figure 5. Effects of HGS-ETR2-Fc on the growth of three primary RCC cell cultures in SCID mice. Plots represent the mean of relative volume of 4 tumors $(2$ mice)/group \pm SD (bars). Mice bearing tumors with a starting volume of $150 \mathrm{~mm}^{3}$ were treated with i.p. injections of $100-\mu \mathrm{g}$ HGS-ETR2Fc (₫) or PBS (๘) daily (horizontal bar indicates 14-day treatment cycle). Tumor volume was monitored during the treatment period and for 2 weeks after cessation of treatment. Although the growth rates of these primary RCC cells varied, the growth of each was significantly inhibited by HGSETR2-Fc. (a) RCC2 ( $\mathrm{P}<0.01)$; (b) RCC4 ( $\mathrm{P}<0.05)$; (c) RCC6 ( $\mathrm{P}<0.01)$.

and b). HGS-ETR2 at a dose of $100 \mu \mathrm{g}$ suppressed tumor growth as effectively as that of HGS-ETR2-Fc in experiment 1. The tumor volume remained the same up to 25 days after initiating the experiment in either $100-\mu \mathrm{g}$ or $300-\mu \mathrm{g}$ HGSETR2-treated mice, however, no animals showed complete tumor elimination. Further histological analysis revealed a significant reduction of tumor cells and an increase of stromal elements in both doses of HGS-ETR2 treatment nude mice (Fig. 6c). An obvious fibrosis and connective tissue at the periphery of the tumor was frequently observed in $100-\mu \mathrm{g}$ HGS-ETR2-treated mice (Fig. 6c, 2), whereas the stromal elements were more commonly observed in the middle of the tumor of 300- $\mu$ g HGS-ETR2-treated mice (Fig. 6c, 3). Because of the extent of connective tissue replacement observed, the actual loss of volume of tumors might be much smaller than the tumor volume measurements would indicate. 
a)

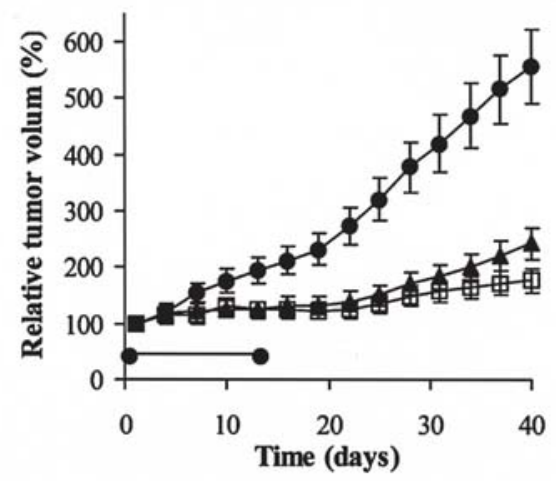

b)
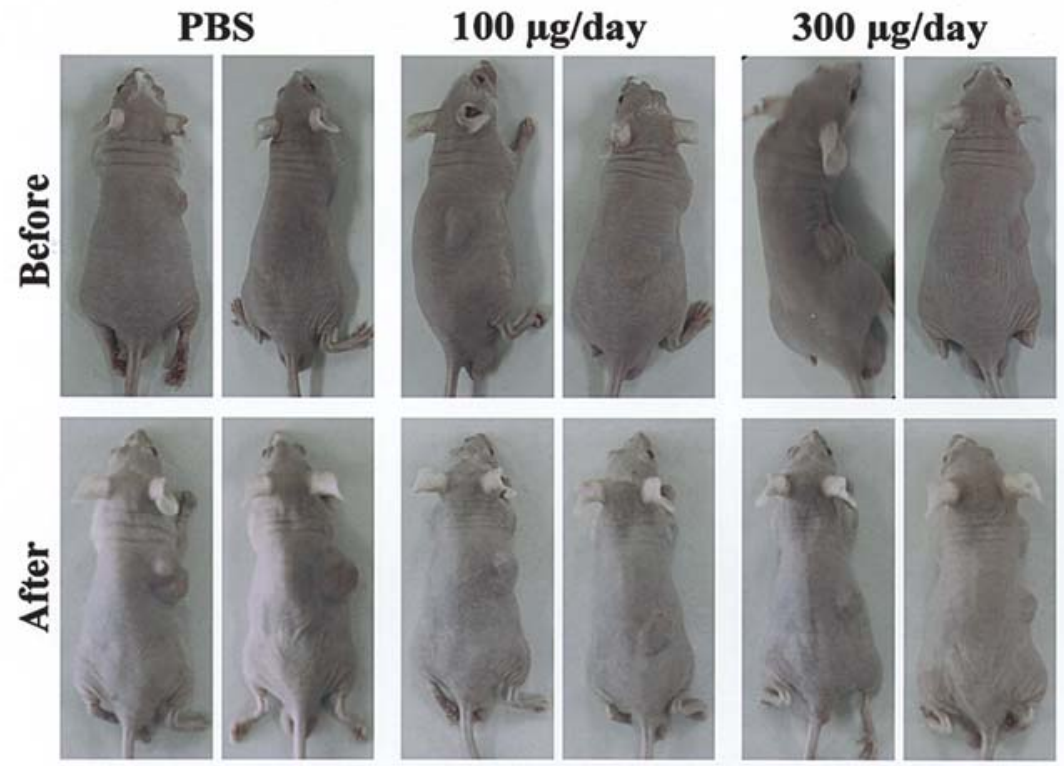

c)
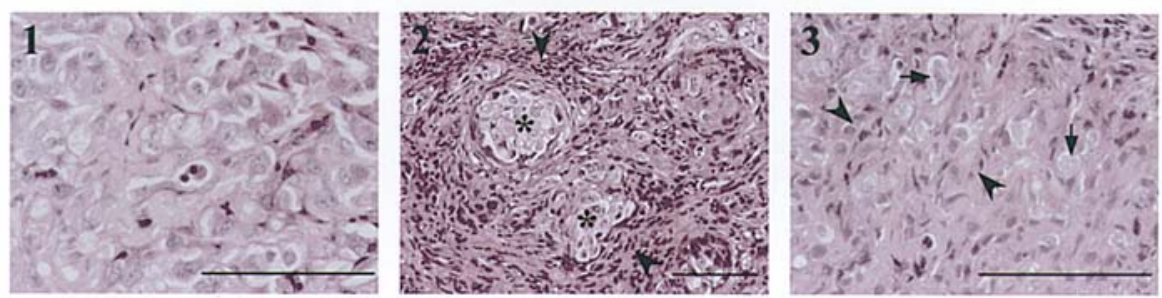

Figure 6. Effects of HGS-ETR2 on a primary RCC cell culture growth in nude mice. (a) Mean relative tumor volume of each group plotted over time. Nude mice (6 per group) received subcutaneous injections with $5 \times 10^{6}$ RCC6 cells and treated with 100- $\left.\mu \mathrm{g}(\mathbf{\Delta}), 300-\mu \mathrm{g}(\lrcorner\right)$ HGS-ETR2, or PBS (•) daily (horizontal bar indicates 14-day treatment cycle). Dose-dependent inhibition of tumor growth was observed and compared to the control group ( $\mathrm{P}<0.01)$. (b) Photograph showing representative mice bearing RCC6 xenografts before and 4 weeks after 14-day treatment of HGS-ETR2. (c) Histological features of RCC6 xenografts after treatment with 100- $\mu \mathrm{g}$ (2), 300- $\mu \mathrm{g}$ (3) HGS-ETR2, or PBS (1). Obvious fibrosis and connective tissue (arrowheads) at the periphery of the tumor (asterisk) was frequently observed in 100- $\mu$ g HGS-ETR2-treated mice, while an increase of stromal elements with some scattered tumor cells (arrows) was often seen in 300- $\mu \mathrm{g}$ HGS-ETR2-treated mice. Scale bars are $200 \mu \mathrm{m}$ in panel (1) and (3), and $400 \mu \mathrm{m}$ in (2).

\section{Discussion}

TRAIL-R mAb-mediated treatment has been shown to be effective in some cancer cell lines $(26,32,33)$, and it is highlighted by the recent introduction of TRAIL-R agonistic antibodies into human Phase I trials (34). In this study, we examined the effects of two new agonistic human mAbs against TRAIL-R1 and TRAIL-R2, TRM-1 and HGS-ETR2, not only on established RCC cell lines, but also on freshly derived RCC cells and xenograft in an attempt to qualify the in vitro and in vivo sensitivity of human primary RCC cells to these agents. We found that: a) HGS-ETR2 induced apoptosis in most of the primary RCC cell cultures, and HGS-ETR2 cross-linked by anti-human IgG Fc was more effective than HGS-ETR2 alone or TRAIL itself in vitro; b) the efficacy of HGS-ETR2 for these RCC cell cultures is likely to depend on the cell-surface expression of TRAIL-R2, and the apoptosis triggered by HGS-ETR2-Fc was caspase- 
dependent; c) in vivo administration of HGS-ETR2-Fc or HGS-ETR2 significantly suppressed tumor growth of subcutaneously inoculated human RCC xenografts in immunodeficient mice. These findings suggest that the HGSETR2-based treatment may be an effective strategy for RCC.

In this study, HGS-ETR2 was as effective as TRAIL itself in all RCC cells except RCC3, which was also insensitive to TRAIL. In accordance with our data, it is reported that human TRAIL-R1 and -R2 mAbs were cytotoxic only to TRAILsensitive cell lines derived from melanoma (35). We found that cytotoxicity of HGS-ETR2 combined with a cross-linker was superior to TRAIL or antibody alone. Similar enhancement of the apoptosis-inducing activity of mAb by cross-linker was observed in CD95 and TRAIL-R1 $(32,35)$. Previous studies suggested that oligomerization of TRAIL-R1 or -R2 can influence cell death signaling $(37,38)$. It is widely accepted that mAbs can have their half-life and agonistic activity improved by modifying the antigen-binding portion or the Fc portion (39-41). A more recent study has demonstrated that besides eliminating most TRAIL-sensitive tumor cells the agonistic TRAIL-R2 mAb can also induce tumor-specific effector and memory $\mathrm{T}$ cells that can eradicate even TRAILresistant tumor variants, and provide long-term protection from tumor recurrence in vivo (33). These results suggest that TRAIL-R2 mAb has an advantage over TRAIL because it has the potential to be modified, and TRAIL-R2 mAb-based therapy is promising for treating cancer.

The cell-surface expression of TRAIL-R1 or -R2 is essential for TRAIL-induced apoptosis, although tumor cells expressing these death receptors are not always sensitive to TRAIL due to intracellular mechanisms (42-45). We have now provided evidence that the surface levels of TRAIL-R1 and -R2 mainly qualify the susceptibility of these primary RCC cells to the $2 \mathrm{mAbs}$, as well as TRAIL. Supporting our data, it has been shown that the efficacy of TRAIL correlates with the cell-surface expression of TRAIL-R1 and/or -R2 in leukemia cells (46). Furthermore, up-regulation of TRAIL-R1 and -R2 by adriamycin (14), 2-methoxyestradiol (47), or IFN- $\alpha$ (48) enhanced the responsiveness of certain cancer cells to TRAIL. Consequently, these observations including ours suggest that TRAIL-R1 or -R2 expression might be a reliable indicator of the degree of cytotoxicity that could be achieved by TRAIL or TRAIL-R mAbs with certain tumors.

It is difficult to examine an isolated TRAIL-mediated signal transduction because various receptors complicate signal transduction. Using the specific mAb, HGS-ETR2, we have been able to evaluate caspase involvement specifically in TRAIL-R2-mediated apoptosis. We found that HGS-ETR2 significantly activated initiative caspases such as caspase-9 and -8 , and effective caspases including caspase- 6 , and -3 in RCC cells. Furthermore, the cell death induced by HGSETR2 was significantly inhibited by the specific caspase inhibitors for caspase- $9,-8$, and -3 , and the general caspase inhibitor Z-VAD-FMK. These results suggest that the caspase cascade plays an important role in anti-TRAIL-R2-mediated apoptosis in RCC cells.

Based on the present in vitro results of this study, the inhibitory effects of HGS-ETR2 on human RCC xenograft growth are clearly demonstrated when administered in vivo.
Although the 3 primary RCC cells examined in this study exhibited prominent heterogeneity in their growth rate in SCID mice, cross-linked HGS-ETR2 significantly inhibited the growth of all of these xenografts. An interesting and different result from in vitro experiments was that HGS-ETR2 alone showed comparable growth inhibitory effects to cross-linked HGS-ETR2 in human RCC xenograft. A similar phenomenon was also found in another study, in which a TRAIL-R1 mAb, $\mathrm{mAb} 4 \mathrm{H} 6$, triggers potent apoptosis upon cross-linking in vitro, but causes complete tumor regression without the addition of exogenous linkers in vivo (33). The mechanism still needs to be clarified, although endogenous oligomerization of $\mathrm{mAb}$ or oligomerization of receptors by $\mathrm{mAb}$ in vivo has been postulated.

Because the HGS-ETR2 used here is not reactive with mouse TRAIL-R2 in normal cells, the potential toxicity of HGS-ETR2 in humans could not be predicted especially when the antibody needs to be crosslinked. Further evaluation of adverse reactions is needed in humans.

In conclusion, we found that TRAIL-R2 mAb, HGSETR2, effectively induces apoptosis in primary RCC cells, in which TRAIL-R2 is frequently expressed. Moreover, it inhibits the tumor growth of subcutaneously inoculated RCC xenografts in immunodeficient mice. These findings provide a foundation for the development of TRAIL-R2 mAb treatment regimens in RCC.

\section{Acknowledgments}

We thank Mr. Kouichi Yube of Research Equipment Center, Faculty of Medicine, Kagawa University, for his technical assistance; we also thank Dr Jessie Wolfe, Human Genome Sciences, for her assistance in preparing the manuscript. This work was supported in part by a Grant-in-Aid for Scientific Research (15591691) from the Ministry of Education, Science, Culture and Sports, Japan.

\section{References}

1. Kartner N, Riordan JR and Ling V: Cell surface P-glycoprotein associated with multidrug resistance in mammalian cell lines. Science 221: 1285-1288, 1983.

2. Slapak CA, Mizunuma N and Kufe DW: Expression of the multidrug resistance associated protein and P-glycoprotein in doxorubicin-selected human myeloid leukemia cells. Blood 84: 3113-3121, 1994.

3. Cole SP, Bhardwaj G, Gerlach JH, et al: Overexpression of a transporter gene in a multidrug-resistant human lung cancer cell line. Science 258: 1650-1654, 1992.

4. Bukowski RM: Cytokine combinations: therapeutic use in patients with advanced renal cell carcinoma. Semin Oncol 27: 204-212, 2000.

5. Motzer RJ, Bander NH and Nanus DM: Renal-cell carcinoma. N Engl J Med 335: 865-875, 1996.

6. Griffith TS and Lynch DH: TRAIL: a molecule with multiple receptors and control mechanisms. Curr Opin Immunol 10: 559-563, 1998.

7. Walczak H, Miller RE, Ariail K, et al: Tumoricidal activity of tumor necrosis factor-related apoptosis-inducing ligand in vivo. Nat Med 5: 157-163, 1999.

8. Van Valen F, Fulda S, Truckenbrod B, et al: Apoptotic responsiveness of the Ewing's sarcoma family of tumours to tumour necrosis factor-related apoptosis-inducing ligand (TRAIL). Int J Cancer 88: 252-259, 2000.

9. Naka T, Sugamura K, Hylander BL, Widmer MB, Rustum YM and Repasky EA: Effects of tumor necrosis factor-related apoptosis-inducing ligand alone and in combination with chemotherapeutic agents on patients' colon tumors grown in SCID mice. Cancer Res 62: 5800-5806, 2002. 
10. Evdokiou A, Bouralexis S, Atkins GJ, Chai F, Hay S, Clayer M and Findlay DM: Chemotherapeutic agents sensitize osteogenic sarcoma cells, but not normal human bone cells, to Apo2L/ TRAIL-induced apoptosis. Int J Cancer 99: 491-504, 2002.

11. Odoux C, Albers A, Amoscato AA, Lotze MT and Wong MK: TRAIL, FasL and a blocking anti-DR5 antibody augment paclitaxel-induced apoptosis in human non-small cell lung cancer. Int J Cancer 97: 458-465, 2002.

12. Singh TR, Shankar S, Chen X, Asim M and Srivastava RK: Synergistic interactions of chemotherapeutic drugs and tumor necrosis factor-related apoptosis-inducing ligand/Apo-2 ligand on apoptosis and on regression of breast carcinoma in vivo. Cancer Res 63: 5390-5400, 2003.

13. Hao C, Song JH, Hsi B, et al: TRAIL inhibits tumor growth but is non-toxic to human hepatocytes in chimeric mice. Cancer Res 64: 8502-8506, 2004.

14. Wu XX, Kakehi Y, Mizutani Y, et al: Enhancement of TRAIL/ Apo2L-mediated apoptosis by adriamycin through inducing DR4 and DR5 in renal cell carcinoma cells. Int J Cancer 104: 409-417, 2003

15. Pan G, Ni J, Wei YF, Yu G, Gentz R and Dixit VM: An antagonist decoy receptor and a death domain-containing receptor for TRAIL. Science 277: 815-818, 1997.

16. Pan G, O'Rourke K, Chinnaiyan AM, et al: The receptor for the cytotoxic ligand TRAIL. Science 276: 111-113, 1997.

17. Chaudhary PM, Eby M, Jasmin A, Bookwalter A, Murray J and Hood L: Death receptor 5, a new member of the TNFR family, and DR4 induce FADD-dependent apoptosis and activate the NF-kappaB pathway. Immunity 7: 821-830, 1997.

18. Ashkenazi A and Dixit VM: Death receptors: signaling and modulation. Science 281: 1305-1308, 1998.

19. Emery JG, McDonnell P, Burke MB, et al: Osteoprotegerin is a receptor for the cytotoxic ligand TRAIL. J Biol Chem 273: 14363-14367, 1998.

20. Marsters SA, Pitti RM, Donahue CJ, et al: Activation of apoptosis by Apo-2 ligand is independent of FADD but blocked by CrmA. Curr Biol 6: 750-752, 1996.

21. Degli-Esposti MA, Dougall WC, Smolak PJ, Waugh JY, Smith CA and Goodwin RG: The novel receptor TRAIL-R4 induces NF-kappaB and protects against TRAIL-mediated apoptosis, yet retains an incomplete death domain. Immunity 7 : 813-820, 1997.

22. Van Valen F, Fulda S, Schafer KL, et al: Selective and nonselective toxicity of TRAIL/Apo2L combined with chemotherapy in human bone tumour cells vs. normal human cells. Int J Cancer 107: 929-940, 2003.

23. Ichikawa K, Liu W, Fleck M, et al: TRAIL-R2 (DR5) mediates apoptosis of synovial fibroblasts in rheumatoid arthritis. J Immunol 171: 1061-1069, 2003.

24. Miranda-Carus ME, Balsa A, Benito-Miguel M, De Ayala CP and Martin-Mola E: Rheumatoid arthritis synovial fluid fibroblasts express TRAIL-R2 (DR5) that is functionally active. Arthritis Rheum 50: 2786-2793, 2004.

25. Jo M, Kim TH, Seol DW, Esplen JE, Dorko K, Billiar TR and Strom SC: Apoptosis induced in normal human hepatocytes by tumor necrosis factor-related apoptosis-inducing ligand. Nat Med 6: 564-567, 2000

26. Ichikawa K, Liu W, Zhao L, et al: Tumoricidal activity of a novel anti-human DR5 monoclonal antibody without hepatocyte cytotoxicity. Nat Med 7: 954-960, 2001.

27. Pukac L, Kanakaraj P, Humphreys R, et al: HGS-ETR1, a fully human TRAIL-receptor 1 monoclonal antibody, induces cell death in multiple tumour types in vitro and in vivo. Br J Cancer 92: 1430-1441, 2005

28. Wu XX, Mizutani Y, Kakehi Y, Yoshida O and Ogawa O: Enhancement of Fas-mediated apoptosis in renal cell carcinoma cells by adriamycin. Cancer Res 60: 2912-2918, 2000.
29. Wu XX, Kakehi Y, Mizutani Y, Lu J, Terachi T and Ogawa O Activation of caspase- 3 in renal cell carcinoma cells by anthracyclines or 5-fluorouracil. Int J Oncol 19: 19-24, 2001.

30. Zhang DY, Wu J, Ye F, et al: Inhibition of cancer cell proliferation and prostaglandin E2 synthesis by Scutellaria baicalensis. Cancer Res 63: 4037-4043, 2003.

31. Green DR and Evan GI: A matter of life and death. Cancer Cell 1: 19-30, 2002.

32. Chuntharapai A, Dodge K, Grimmer K, et al: Isotype-dependent inhibition of tumor growth in vivo by monoclonal antibodies to death receptor 4. J Immunol 166: 4891-4898, 2001.

33. Takeda K, Yamaguchi N, Akiba H, et al: Induction of tumorspecific $\mathrm{T}$ cell immunity by anti-DR5 antibody therapy. J Exp Med 199: 437-448, 2004.

34. Reed JC: Apoptosis-targeted therapies for cancer. Cancer Cell 3: $17-22,2003$

35. Griffith TS, Rauch CT, Smolak PJ, et al: Functional analysis of TRAIL receptors using monoclonal antibodies. J Immunol 162: 2597-2605, 1999.

36. Dhein J, Daniel PT, Trauth BC, Oehm A, Moller P and Krammer PH: Induction of apoptosis by monoclonal antibody anti-APO-1 class switch variants is dependent on cross-linking of APO-1 cell surface antigens. J Immunol 149: 3166-3173, 1992.

37. Banner DW, D'Arcy A, Janes W, et al: Crystal structure of the soluble human $55 \mathrm{kDa}$ TNF receptor-human TNF beta complex: implications for TNF receptor activation. Cell 73: 431-445, 1993.

38. Lee H, Trainer AH, Friedman LS, Thistlethwaite FC, Evans MJ, Ponder BA and Venkitaraman AR: Mitotic checkpoint inactivation fosters transformation in cells lacking the breast cancer susceptibility gene, Brca2. Mol Cell 4: 1-10, 1999.

39. Clark M: Antibody humanization: a case of the 'Emperor's new clothes'? Immunol Today 21: 397-402, 2000.

40. Carter P: Improving the efficacy of antibody-based cancer therapies. Nat Rev Cancer 1: 118-129, 2001.

41. Waldmann TA: Immunotherapy: past, present and future. Nat Med 9: 269-277, 2003.

42. Amantana A, London CA, Iversen PL and Devi GR: X-linked inhibitor of apoptosis protein inhibition induces apoptosis and enhances chemotherapy sensitivity in human prostate cancer cells. Mol Cancer Ther 3: 699-707, 2004.

43. Johnson TR, Stone K, Nikrad M, et al: The proteasome inhibitor PS-341 overcomes TRAIL resistance in Bax and caspase 9-negative or Bcl-xL overexpressing cells. Oncogene 22: 4953-4963, 2003

44. Wang CY, Mayo MW, Korneluk RG, Goeddel DV and Baldwin AS Jr: NF-kappaB antiapoptosis: induction of TRAF1 and TRAF2 and c-IAP1 and c-IAP2 to suppress caspase- 8 activation. Science 281: 1680-1683, 1998.

45. Chen C, Edelstein LC and Gelinas C: The Rel/NF-kappaB family directly activates expression of the apoptosis inhibitor $\mathrm{Bcl}-\mathrm{x}(\mathrm{L})$. Mol Cell Biol 20: 2687-2695, 2000.

46. Liu Q, Hilsenbeck S and Gazitt Y: Arsenic trioxide-induced apoptosis in myeloma cells: p53-dependent G1 or G2/M cell cycle arrest, activation of caspase- 8 or caspase- 9 , and synergy with APO2/TRAIL. Blood 101: 4078-4087, 2003.

47. La Vallee TM, Zhan XH, Johnson MS, et al: 2-Methoxyestradiol up-regulates death receptor 5 and induces apoptosis through activation of the extrinsic pathway. Cancer Res 63: 468-475, 2003.

48. Shigeno M, Nakao K, Ichikawa $\mathrm{T}$, et al: Interferon-alpha sensitizes human hepatoma cells to TRAIL-induced apoptosis through DR5 upregulation and NF-kappa B inactivation. Oncogene 22: 1653-1662, 2003. 